\title{
sciendo
}

Research Article

(C) 2019 Amal El Kharouf and Nour Daoud. This is an open access article licensed under the Creative Commons

Attribution-NonCommercial-NoDerivs License (http://creativecommons.org/licenses/by-nc-nd/3.0/).

\section{Gender Role Attitudes among Higher Education Students in Jordan}

\author{
Amal El Kharouf \\ Professor, Women's Studies Program, \\ University of Jordan, Jordan

\section{Nour Daoud}

Ph.D. Candidate, Social Sciences: Interaction, Communication and Cultural Construction Program, University of Padova, Italy

Doi: $10.2478 / \mathrm{mjss}-2019-0053$

\begin{abstract}
Youth are the change agents of any society, therefore, it is critical to identify their attitudes toward gender roles. The study utilizes a social survey approach, where a stratified random sample is selected from the study population, which consists of Jordanian youth who are enrolled at the University of Jordan in Amman, Jordan. The size of the sample is 848 youth, with $33.5 \%(N=284)$ males and $66.5 \%$ females ( $N=564)$. A survey, based on two scales, is developed to measure youth's attitudes toward gender roles: the gender professions scale and the gender skills scale. The study also examines the effect of the following variables: age, type of college, place of residence, monthly income, and educational level of the mother. The analysis uses statistical methods to recognize differences in attitudes, to understand the relationship between the independent and dependent variables, and to determine statistical significance (set at $p \leq 0.05$ ). The results show that the attitudes of female youth toward gender roles are nontraditional in comparison to those of their male counterparts. Moreover, attitudes toward gender roles tend to be gender-balanced among older youth who live in urban areas, study in humanitarian colleges, and whose mother's educational level is high. The study highlights the importance of institutionalizing the concept of gender in higher educational institutions.
\end{abstract}

Keywords: developing societies, educational institutions, gender-balanced attitudes, Jordan, Middle-East, socialization

\section{Introduction}

Gender is a sociocultural process that is constantly being produced and reproduced (Wharton, 2012). It is defined as masculine and feminine properties that are culturally and psychologically formed and developed within society (Kessler and McKenna, 2001). Gender differs from the concept of sex, which refers to the physiological and biological characteristics that distinguish males and females (Oakley, 1991; Lindsey, 2015). Gender is important due to its role in shaping relations of inequality that arise from the biological differences according to which social resources and privileges are distributed.

Gender roles are the acts that men and women are expected to perform according to their sex, and such roles are produced through the interaction of individuals with their environments (Lindsey, 2015), as well as through the stereotyping process, which forms an image in the individual's mind that is not based on personal experience but derived from the culture and surrounding environment (Lippmann, 1994). This image is generally simple and inaccurate, as it is 
attained via transference between individuals. Traditional gender attitudes link the roles and functions of women in society to typical female characteristics, such as emotionality. Therefore, females are given the responsibilities of caring for the home or performing certain occupations, such as nursing. This is no different for men, who are linked to traditional male characteristics, such as rationality and responsibility in making important family decisions.

Many modern societies are interested in combating traditional gender notions and providing equal opportunities for men and women. In their book Rising tide: Gender equality and cultural change around the world, Inglehart and Norris (2003) examined how traditional attitudes toward gender roles in 70 countries changed during the 20th century, including Jordan, which ranked low compared to rich industrial and post-industrial countries. In the current century, Jordan, a Middle Eastern developing country affected by surrounding crises and political conflicts, seeks to move from the stage of "Neopatriarchy" (Sharabi, 1992) to modernity, especially with regard to gender equality, through all its institutions. Jordon ratified the Convention on the Elimination of All Forms of Discrimination against Women (CEDAW) in 1992, acknowledging women's rights as human rights that cannot be violated in any context. The results of the latest report from the CEDAW Committee showed several positive temporary measures that have been taken in Jordan to accelerate gender equality. For example, the Municipalities Law for 2011 has increased the proportion assigned to women in the municipal councils from $20 \%$ to $25 \%$ (CEDAW, 2016). However, CEDAW experts have expressed concerns about Jordan's decline in rank, to 140th, in gender equality. They have called on Jordan to make effective use of temporary special measures to counter customs and beliefs that hinder the full participation of women in public and economic life (Reliefweb, 2017).

The youth are the leaders of change in any society, so it is necessary to study their attitudes toward gender roles within the various institutions that affect their social upbringing. We will focus here on higher education institutions, as represented by the University of Jordan, the main university in Jordan, as we are aware of the role of these institutions in reproducing gender roles across generations. Knowing youth's attitudes toward gender roles, whether traditional, nontraditional, or gender-balanced, ${ }^{1}$ will help highlight the role of Jordan's higher education institutions in bridging the gender gap and achieving gender equality.

\section{Theorizing Gender Role Attitudes (GRA)}

Many theories address the concept of gender roles, including biological scientific theories, psychological approaches, sociocultural views, and feminist thought. Biological theories focus on the body organs and biological and hormonal differences between the two sexes to explain the attraction of women to female gender roles and men's tendency to choose male gender roles. As for the psychological theories, Freud's psychoanalysis theory argued that gender development occurs in the third stage, which is called the phallic stage, which occurs between the ages of three and six. Freud noted that gender development varied between boys and girls, and he explained this as follows: The boy takes on the gender role of his father in an attempt to solve the Oedipus complex, which is generated through his jealousy of his father and his desire to possess his mother; the girl unravels the Electra complex, taking on her mother's gender role in an attempt to possess her father (Lindsey, 2015). Object Relations theory, which has been used by many theorists, such as Chodorow, affirms that gender roles are formed during childhood through the mother, who is considered in many societies to be the first educator of her children. For Chodorow, the mother sees her daughter as an extension of herself, so she associates herself with her daughter in a narcissistic way. Consequently, the daughter grows up representing her mother and exercising her gender roles. With the son, the mother's awareness that he is different from her gives her the courage to separate him from her female world so that he will grow up performing male gender

\footnotetext{
1 Traditional gender attitudes are trends that depend on social and cultural stereotyping to link roles, professions, and skills to one gender and not the other. In contrast, nontraditional gender attitudes are trends whose followers refuse to depend upon stereotyping to determine gender roles, always supporting the opposite direction. A gender-balanced attitude is a trend whose followers adopt impartiality in terms of gender rolemodeling, skills, and professions, without seeing any gender as monopolizing these.
} 
roles (Chodorow, 1978, 1992). Furthermore, Social Learning theory sheds light on the socialization process, suggesting that children acquire gender roles through the processes of observation, imitation, simulation, and modeling of the similar sex, and these roles are enhanced through reward and punishment (Bandura, 2002). The Theory of Cognitive Development contradicts the later theory, affirming that the child's understanding of gender evolves through different stages of life. This starts with the "gender identity" stage, which is when the child realizes that he or she is a boy or a girl; it is followed by the "gender stability" stage, which stresses the child's recognition that his/her gender identity does not change over time; finally, in the "gender consistency" stage, gender identity does not alter with the appearance, clothing, or characteristics of the individual. This is not achieved through social learning processes, but rather through the cognitive maturation of children, who become aware of gender roles that must be practiced in society according to their age (Martin et al., 2002). All previous cognitive theories contributed to the development of Gender Schema theory, which argues that children develop what it means to be male and female at early ages, using gender schemata to classify information, make decisions, and behave in a certain manner (Starr \& Zurbriggen, 2016). For Sandra Bem, the pioneer of this theory, gender roles are defined by the culture around us. A child who grows up in a traditional gender environment has gender schemata that reinforce his/her traditional gender roles, while a child born in a gender-balanced environment that does not depend on biological differences has a balanced, androgenic personality that combines male and female characteristics (Bem, 1983).

One well-known sociological theory is Social Role theory, which posits that the social roles of men and women, which are built historically, culturally, and socially, are based on the principle of division of labor according to physical characteristics. This theory has played a significant role in the development of theories regarding gender roles and behaviors expected of men and women (Eagly et al., 2000). Refusal to perform these roles may surprise and confuse others, as this contradicts the established societal norms and may threaten social relations and cohesion (Harrison \& Lynch, 2005). In Gender Socialization theory, gender roles are acquired through various institutions over two stages: the primary stage (with family) and the secondary stage (at school, through friends, or through other institutions, such as media) (Berger \& Luckmann, 1991). This theory argues that the educational system in general play an important role in achieving gender equality (Sadker et al., 2009).

Finally, it is vital to address some feminist views, which play an important role in dismantling stereotypes about gender roles and providing balanced gender attitudes based on the principle of equality between men and women. Liberal feminism defends women's rationality and decisionmaking capacity and considers education to be critical in liberating women from their traditional gender roles (Lindsey, 2015). Radical feminism argues that gender equality is to be achieved only through challenging the patriarchal system, which benefits from women performing nonproductive gender roles (Bryson, 1995). Socialist feminism focuses on ending sexism by eradicating "the interrelationships between capitalism and patriarchy as expressed through the sexual division of labor" (Eisenstein, 1990, p.197).

In sum, all the above theories aim to explain the formation and acquisition of gender roles, and all contain elements of validity. There are considerable contradictions, limitations, and sometimes overlap among them; however, we cannot underestimate the importance of each in that each addresses gender discrimination from a different perspective.

\section{Literature Review}

There are several studies that describe the effects of different variables on gender role attitudes among youth and adolescents. Previous literature has noted that attitudes toward gender roles vary between male and female youth. Al Kharouf and Al Bdour (2006) found that the attitudes among male youth in the city of Al-Tafilah in Jordan were more traditional than those of females, especially regarding making final decisions in the family. Similarly, studies Fan and Marini (2000), Mensch et al. (2004), Japaridze et al. (2013), Hajnalka (2014) found that female youth in the US, Egypt, Georgia, Central and Eastern Europe, respectively, had less traditional gender attitudes than their male counterparts. 
As for the age variable, LaFont's (2010) study in Namibia revealed that younger youth (16 years old) were more responsive to gender equality than older youth (20 years old). This was confirmed by Tinklin et al. (2005), who found that young people between the ages of 16 and 17 believed in the right of both males and females to complete their higher education, and that the responsibility of caring for children should be a joint responsibility between the spouses. Similarly, Obare et al. (2013) confirmed the inclination of older adolescent females in Kenya to reveal more conservative views concerning decision making within the household compared to their younger counterparts. However, Watts and Borders (2005) pointed out that youth in adolescence are subject to societal pressures and thus develop their traditional gender roles based on prevailing stereotypes in society.

On the other hand, LaFont (2010) found that younger youth living in cities had less traditional attitudes toward gender roles when compared to younger youth who lived in rural areas and villages. This was also confirmed by Japaridze et al. (2013) and Shteiwi (2015). However, these results were rejected by Hajnalka (2014), who found no difference between university students living in cities and those living in rural areas.

Furthermore, Tallichet and Willits (1986) found that young women with high educational and economic status showed less traditional attitudes toward gender roles, a result echoed by Japaridze et al. (2013). However, in Egypt and Sri Lanka, Mensch et al., (2004) and Wijewadene (2016) noted that the level of education, openness, and technological advancement did not change the traditional perceptions of youth about the gender roles. Finally, Shteiwi (2015) pointed out that, in Jordan, an individual's gender role attitudes tended to be more traditional if the individual had a Master's degree or above.

Additionally, the results of Baruch and Barnett (1986) indicated that girls whose mothers supported more equitable gender roles, developed more egalitarian attitudes over time. Likewise, the study of Fan and Marini (2000, p.279) presented that American youth "whose parents were more highly educated and whose mothers were employed had more egalitarian gender-role attitudes than those whose parents were less well-educated and whose mothers were not employed". On another note, Updegraff et al. (2014) confirmed that when Mexican-American mothers reported more stereotypical attitudes toward gender roles, their adolescents reported the same.

Finally, in various quantitative studies such as Foshee and Bauman (1992), Evertsson (2006) and Hess et al. (2014) adolescents from higher social-economic status generally conveyed more equitable gender role attitudes.

\section{Methodology}

The population of the study consists of all female and male youth who are enrolled at the University of Jordan during the academic year 2017-2018. A stratified random sample of students is extracted, where the total number of students is $848,284(33.5 \%)$ of whom are male and $564(66.5 \%)$ of whom are female, taking into account the distribution of students by college.

The study adopts a social survey approach. The survey has three parts. The first focuses on the demographic, social, and economic characteristics of the student. The second consists of the gender professions scale, and third part includes the gender skills scale. The two scales are sensitively developed in line with the Jordanian context. For each separate paragraph, scores between 1 and 3 are given for the participants' responses to the two scales used to measure attitudes toward gender roles, where 1 is given for a traditional attitude, 2 for a nontraditional attitude, and 3 for a gender-balanced attitude (see Appendix 1).

Before the implementation phase of the study, the validity of the tool was verified through a pilot experiment in which 40 surveys were distributed. This experiment was repeated two weeks after the date of the pre-test experiment with the same respondents. Pearson correlation coefficients were calculated between the pre-test results and the post-experiment results, and all were greater than $80 \%$ ( $85 \%$ for the professions scale and $92 \%$ for the skills scale), indicating a high level of stability in the survey used.

Having developed, reviewed, and validated the survey, and upon obtaining approval from the 
University of Jordan to implement the study, the survey was distributed to all sample members. Prior to data collection, the objectives of the study were explained to each member, as well as their right to refuse to answer the survey or any part of it, and the participants were told that their responses would remain confidential.

This study is based on statistical methods such as arithmetical means and standard deviations. Moreover, some tests were used to address the objectives of the study, including t-tests and one-way ANOVAs. These enabled the recognition of differences in attitudes and an understanding of the relationship between the independent variables (gender, age, college, place of residence, monthly income of the family, educational level of the mother) and the dependent variable (attitudes of young people toward gender roles in terms of professions and skills); these tests also revealed any statistical significance at the level of $p \leq 0.05$.

For the purposes of determining students' attitudes toward gender roles on the skills and professions scales, the mathematical averages of the responses were divided into the following categories: $1-1.74=$ traditional gender attitude; $1.75-2.24=$ nontraditional gender attitude; and 2.25-3 = gender-balanced attitude.

\section{Results}

\subsection{Students' Attitudes Toward Gender Roles According to Gender}

Table (1) shows the arithmetic means and standard deviations of the participants' responses to the gender skills scale, for which they were asked to decide whether a given skill was suitable for males, females, or both. The females' overall average response was higher than that of the males, at 2.13 and 1.73, respectively. The highest average among female responses was 2.43, corresponding to the paragraph that refers to the "reception of guests," while the lowest was 1.56, on the paragraph referring to "training on car driving." As for males, the highest average response was 2.02, on the paragraph on "cooking," while the lowest average male response was 1.22 , on the paragraph that refers to "replacing gas cylinder."

Table 1: Students' Attitudes Toward Appropriate Skills for Genders by Student Gender

\begin{tabular}{|c|c|c|c|c|c|}
\hline \multirow{3}{*}{ \# } & \multirow{3}{*}{ Skill } & \multicolumn{4}{|c|}{ Gender } \\
\hline & & \multicolumn{2}{|c|}{ Male } & \multicolumn{2}{|c|}{ Female } \\
\hline & & Arithmetic Mean & Standard Deviation & Arithmetic Mean & Standard Deviation \\
\hline 1 & Setting the table & 1.65 & 0.57 & 2.03 & 0.83 \\
\hline 2 & Washing the dishes & 1.86 & 0.49 & 2.25 & 0.88 \\
\hline 3 & Washing the clothes & 1.85 & 0.54 & 2.15 & 0.84 \\
\hline 4 & Buying the newspaper & 1.64 & 0.78 & 2.39 & 0.75 \\
\hline 5 & Using the Internet & 1.74 & 0.85 & 2.40 & 0.69 \\
\hline 6 & Buying household items & 1.67 & 0.72 & 2.41 & 0.69 \\
\hline 7 & Replacing gas cylinder & 1.22 & 0.55 & 2.15 & 0.70 \\
\hline 8 & Ironing & 2.00 & 0.63 & 2.07 & 0.92 \\
\hline 9 & Reception of guests & 1.72 & 0.84 & 2.43 & 0.69 \\
\hline 10 & Home maintenance & 1.66 & 0.81 & 1.97 & 0.95 \\
\hline 11 & Training on car driving & 1.74 & 0.78 & 1.56 & 0.71 \\
\hline & Cooking & 2.02 & 0.69 & 1.73 & 0.57 \\
\hline & Total & 1.73 & 0.37 & 2.13 & 0.55 \\
\hline
\end{tabular}

Table (2) shows the arithmetic means and standard deviations of the participants' responses on the gender professions scale, in which they were asked to decide whether certain professions were suitable for males, females, or both. The females' overall average response on this scale was higher than that of the males, at 2.07 and 1.65, respectively. The highest average male response on this scale was for the air host/hostess profession, with 2.09, while the highest average female responses were for teaching, nursing, gynecology, and obstetrics professions, all of which had an average score of 2.43 . 
Table 2: Students' Attitudes Toward Appropriate Professions for Genders by Student Gender

\section{\# Profession}

1 Teaching

2 Working in the press

3 Defense careers (such as military and civil defense)

4 Holding a ministerial post

5 TV or radio director

6 Management (companies, factories, individuals, institutions)

7 Nursing

8 Presenting television or radio programs

9 Agricultural work

10 Secretarial work

11 Working in police (traffic, criminal investigation)

12 Aircraft pilot

13 Work in the general intelligence

14 Taxi driver

15 Judge

16 Car mechanic

17 Working in construction (selling, buying,

building, leasing lands and houses)

18 Ambassador of the state

19 Air host/hostess

20 Lawyer

21 Engineering professions

22 Sewing work

23 Gynecology and obstetrics

24 Surgery and anesthesia

25 Producing television or radio programs Total

\begin{tabular}{|c|c|c|c|}
\hline \multicolumn{4}{|c|}{ Gender } \\
\hline \multirow{3}{*}{$\frac{\underline{\text { Male }}}{\underline{\text { Arithmetic }}} \frac{\text { Mean }}{\underline{\text { Mean }}}$} & \multirow{2}{*}{\multicolumn{2}{|c|}{$\begin{array}{l}\text { Female } \\
\text { ard Arithmetic }\end{array}$}} & \multirow{3}{*}{$\frac{\text { Standard }}{\text { Deviation }}$} \\
\hline & & & \\
\hline & Deviation & Mean & \\
\hline 2.00 & 0.00 & 2.43 & 0.69 \\
\hline 2.02 & 0.69 & 2.22 & 0.92 \\
\hline 1.00 & 0.00 & 2.22 & 0.92 \\
\hline 1.00 & 0.00 & 1.87 & 0.93 \\
\hline 2.02 & 0.69 & 2.22 & 0.92 \\
\hline 2.02 & 0.69 & 1.55 & 0.82 \\
\hline 2.00 & 0.00 & 2.43 & 0.69 \\
\hline 2.00 & 0.00 & 2.27 & 0.66 \\
\hline 2.02 & 0.69 & 2.22 & 0.92 \\
\hline 2.00 & 0.06 & 1.97 & 0.45 \\
\hline 1.00 & 0.00 & 1.52 & 0.81 \\
\hline 2.02 & 0.69 & 2.22 & 0.92 \\
\hline 1.00 & 0.00 & 1.80 & 0.92 \\
\hline 1.30 & 0.46 & 2.22 & 0.92 \\
\hline 1.30 & 0.46 & 2.22 & 0.92 \\
\hline 1.30 & 0.46 & 2.22 & 0.92 \\
\hline 1.30 & 0.46 & 2.22 & 0.92 \\
\hline 1.30 & 0.46 & 2.22 & 0.92 \\
\hline 2.09 & 0.63 & 2.23 & 0.64 \\
\hline 2.02 & 0.69 & 1.37 & 0.77 \\
\hline 2.02 & 0.69 & 2.22 & 0.92 \\
\hline 1.72 & 0.84 & 2.00 & 0.00 \\
\hline 1.72 & 0.84 & 2.43 & 0.69 \\
\hline 1.00 & 0.00 & 1.36 & 0.69 \\
\hline 2.02 & 0.69 & 2.22 & 0.92 \\
\hline 1.65 & 0.28 & 2.07 & 0.64 \\
\hline
\end{tabular}

Note: 1-1.74: traditional attitude; 1.75-2.24: nontraditional attitude; $2.25-3$ : gender-balanced attitude.

Table (3) shows the results of the t-test, which help us to better understand the differences between the participants' average scores on both the gender professions and the gender skills scales. There are statistically significant differences between male and female students on the gender skills scale, in favor of females, for whom the value of $t$ is 11.00, and its statistical significance is $p<0.000$. In general, female attitudes toward gender roles on this scale are nontraditional, with an average of 2.13, while male attitudes are traditional, with an average of 1.73. Furthermore, there are also statistically significant differences between males and females on the gender professions scale, in favor of females, for whom the value of $t$ is $10.75(p<0.000)$. Female attitudes toward gender roles on this scale are also nontraditional, at an average of 2.07 , compared to males at 1.65 .

Table 3: T-test Results for Gender Role Attitudes by Student Gender

\begin{tabular}{llccccc}
\hline Scale & Gender & Number & Arithmetic Mean & Standard Deviation & Value of $\boldsymbol{t}$ & Sig. \\
\hline Gender skills & Male & 284 & 1.73 & 0.37 & 11.00 & 0.000 \\
& Female & 564 & 2.13 & 0.55 & & \\
Gender professions & Male & 284 & 1.65 & 0.28 & 10.75 & 0.000 \\
& Female & 564 & 2.07 & 0.64 & 10.75
\end{tabular}

Note: 1-1.74: traditional attitude; 1.75-2.24: nontraditional attitude; 2.25-3: gender-balanced attitude.

\subsection{Students' Attitudes toward Gender Roles according to Student Age and Place of Residence}

Table (4) shows the differences between the average student attitudes with respect to gender roles 
according to the students' age and their place of residence. ${ }^{2}$

Table 4: Students' Attitudes Toward Appropriate Gender Roles by Student Age and Place of Residence

\begin{tabular}{llccc}
\hline Scale & Age & Number & Arithmetic Mean & Standard Deviation \\
\hline \multirow{3}{*}{ Gender skills } & $<18$ years old & 253 & 1.77 & 0.37 \\
& 18-22 years & 132 & 1.59 & 0.16 \\
Gender professions & $>$ 22 years & 463 & 2.23 & 0.55 \\
& $<18$ years old & 253 & 1.48 & 0.34 \\
& 18-22 years & 132 & 1.51 & 0.23 \\
& $>$ 22 years & 463 & 2.30 & 0.49 \\
\hline Scale & Place of Residence & Number & Arithmetic Mean & Standard Deviation \\
\hline Gender skills & Outside Amman & 456 & 1.82 & 0.39 \\
& Eastern Amman & 131 & 1.96 & 0.59 \\
Gender professions & Western Amman & 261 & 2.33 & 0.56 \\
& Outside Amman & 456 & 1.63 & 0.46 \\
& Eastern Amman & 131 & 2.08 & 0.61 \\
& Western Amman & 261 & 2.37 & 0.42 \\
\hline
\end{tabular}

Note: 1-1.74: traditional attitude; 1.75-2.24: nontraditional attitude; 2.25-3: gender-balanced attitude.

To determine whether these differences are statistically significant, a one-way ANOVA was applied, the results of which are shown in Table (5).

Table 5: Results of One-Way ANOVA for Gender Role Attitudes Based on Student Age and Place of Residence

\begin{tabular}{|c|c|c|c|c|c|c|}
\hline Scale & Source of Variance & Sum of Squares & DF & Mean Squares & F Value & Sig. \\
\hline \multirow{3}{*}{ Gender Skills } & Between groups & 60.35 & 2 & 30.17 & \multirow{3}{*}{142.48} & \multirow{3}{*}{0.000} \\
\hline & Within groups & 178.96 & 845 & 0.21 & & \\
\hline & Total & 239.31 & 847 & & & \\
\hline \multirow{3}{*}{ Gender professions } & Between groups & 135.88 & 2 & 67.94 & \multirow{3}{*}{386.24} & \multirow{3}{*}{0.000} \\
\hline & Within groups & 148.64 & 845 & 0.18 & & \\
\hline & Total & 284.52 & 847 & & & \\
\hline Scale & Source of Variance & Sum of Squares & DF & Mean Squares & F Value & Sig. \\
\hline \multirow[t]{3}{*}{ Gender skills } & Between groups & 42.89 & 2 & 21.44 & \multirow{3}{*}{92.26} & \multirow{3}{*}{0.000} \\
\hline & Within groups & 196.42 & 845 & 0.23 & & \\
\hline & Total & 239.31 & 847 & & & \\
\hline \multirow[t]{3}{*}{ Gender Professions } & Between groups & 94.14 & 2 & 47.07 & \multirow{3}{*}{208.93} & \multirow{3}{*}{0.000} \\
\hline & Within groups & 190.38 & 845 & 0.23 & & \\
\hline & Total & 284.52 & 847 & & & \\
\hline
\end{tabular}

It is clear from Tables (4) and (5) that the highest average responses with respect to attitudes on the gender skills scale belong to the third age group, which is the eldest (> 22 years), where the average response to this category is 2.23 and therefore nontraditional. The highest average responses on the gender professions scale are also for the third age group, with an average response of 2.30; here, the students' attitudes are gender-balanced. The results of the one-way ANOVA based on student age show statistically significant differences on both scales, where the $F$ value is 142.48 for gender skills and 386.42 for gender professions ( $p<0.000$ for both).

As for the place of residence variable, it can be seen in tables (4) and (5) that the highest average responses on the gender skills and professions scales are from participants from West Amman, at 2.33 and 2.37, respectively. The results of the one-way ANOVA show statistically significant differences on both scales, where the $F$ value is 92.26 for gender skills and 208.93 for gender professions ( $p<0.000$ for both).

\footnotetext{
${ }^{2}$ There are huge differences, particularly in socioeconomic terms, between Amman East, Amman West, and
} areas outside Amman. 


\subsection{Students' Attitudes Toward Gender Roles Based on Students' College}

Table (6) displays the results of the t-test, which help us to better understand the difference between the average responses according to the variable of student college. The average responses of students enrolled in humanitarian colleges are higher those of students registered at scientific colleges. The results of the t-test show statistically significant differences between the students' attitudes according to the college variable on both the gender profession and skill scales, in favor of the humanitarian colleges, with t-values at 7.66 and 11.50 , respectively $(p<0.000)$.

Table 6: Results of T-test for Gender Role Attitudes Based on Students' College Type

\begin{tabular}{llccccc}
\hline Scale & College & Number & $\begin{array}{c}\text { Arithmetic } \\
\text { Mean }\end{array}$ & $\begin{array}{c}\text { Standard } \\
\text { Deviation }\end{array}$ & $\begin{array}{c}\text { Value of } \\
\boldsymbol{t}\end{array}$ & $\begin{array}{c}\text { Significance } \\
\text { Level }\end{array}$ \\
\hline \multirow{2}{*}{ Gender skills } & Scientific & 453 & 1.87 & 0.43 & 7.66 & 0.000 \\
\multirow{2}{*}{ Gender profession } & Humanitarian & 395 & 2.14 & 0.60 & & \\
& Scientific & 453 & 1.73 & 0.49 & 11.50 & 0.000 \\
& Humanitarian & 395 & 2.16 & 0.59 & &
\end{tabular}

Note: 1-1.74: traditional attitude; 1.75-2.24: nontraditional attitude; 2.25-3: gender-balanced attitude.

\subsection{Students' Attitudes Toward Gender Roles Based on Students' Monthly Income and their Mother's Educational Level}

Table (7) shows the differences between the students' average attitudes according to their monthly income ${ }^{3}$ and their mother's educational level.

Table 7: Students' Attitudes Toward Appropriate Gender Roles Based on Students' Monthly Income and Mother's Educational Level

\begin{tabular}{llccc}
\hline Scale & Monthly Income & Number & Arithmetic Mean & Standard Deviation \\
\hline \multirow{5}{*}{ Gender skills } & $<200$ & 85 & 1.60 & 0.17 \\
& $200-<400$ & 184 & 1.73 & 0.42 \\
& $400-<600$ & 127 & 1.83 & 0.33 \\
& $600-<800$ & 201 & 2.04 & 0.47 \\
& 800 or above & 251 & 2.37 & 0.57 \\
Gender professions & $<200$ & 127 & 1.50 & 0.34 \\
& $200-<400$ & 85 & 1.51 & 0.42 \\
& $400-<600$ & 184 & 1.58 & 0.42 \\
& $600-<800$ & 201 & 2.13 & 0.55 \\
\hline Scale & 800 or above & 251 & 2.39 & 0.12 \\
\hline Gender skills & Mother's Educational Level & Number & Arithmetic Mean & Standard Deviation \\
& Illiterate & 109 & 1.51 & 0.19 \\
& Primary & 101 & 1.54 & 0.41 \\
& Preparatory & 132 & 1.73 & 0.09 \\
& Secondary & 18 & 1.75 & 0.28 \\
& Community college & 115 & 1.77 & 0.15 \\
& Bachelor's & 133 & 2.42 & 0.00 \\
Gender professions & Postgraduate & 240 & 2.44 & 0.31 \\
& Illiterate & 18 & 1.28 & 0.22 \\
& Primary & 115 & 1.44 & 0.45 \\
& Preparatory & 101 & 1.52 & 0.10 \\
& Secondary & 132 & 1.54 & 0.17 \\
& Community college & 109 & 1.66 & 0.50 \\
\hline & Bachelor's & 133 & 2.42 & \\
& Postgraduate & 240 & 2.45 &
\end{tabular}

Note: 1-1.74: traditional attitude; 1.75-2.24: nontraditional attitude; 2.25-3: gender-balanced attitude.

\footnotetext{
${ }^{3} 100$ Jordanian Dinar is equal to almost 122 Euro.
} 
To determine whether these differences are statistically significant, a one-way ANOVA was applied, the results of which are shown in Table 8.

Table 8: Results of One-Way ANOVA for Gender Role Attitudes based on Students' Monthly Income and Mother's Educational Level

\begin{tabular}{llccccc}
\hline Scale & Source of Variance & Sum of Squares & DF & Mean Squares & F Value & Sig. \\
\hline \multirow{3}{*}{ Gender skills } & Between groups & 65.12 & 4 & 16.28 & \multirow{2}{*}{78.79} & 0.000 \\
& Within groups & 174.19 & 843 & 0.21 & & \\
& Total & 239.31 & 847 & & & \\
Gender professions & Between groups & 121.71 & 4 & 30.43 & 157.55 & 0.000 \\
& Within groups & 162.81 & 843 & 0.19 & & \\
& Total & 284.52 & 847 & & & \\
\hline Scale & Source of Variance & Sum of Squares & DF & Mean Squares & F Value & Sig. \\
\hline Gender skills & Between groups & 135.08 & 6 & 22.51 & 181.66 & 0.000 \\
& Within groups & 104.23 & 841 & 0.12 & & \\
\multirow{2}{*}{ Gender professions } & Total & 239.31 & 847 & & & \\
& Between groups & 179.00 & 6 & 29.83 & 237.75 & 0.000 \\
& Within groups & 105.53 & 841 & 0.13 & & \\
\hline
\end{tabular}

It can be seen in Tables (7) and (8) that the highest average responses on the gender skills and professions scales are in from those with a monthly income above 800, with average responses of 2.37 and 2.39, respectively. The results of the one-way ANOVA show statistically significant differences on both the gender skills and the professions scales, with $\mathrm{F}$ values of 78.79 and 157.55 , respectively ( $p<0.000$ for both). The tables also show that the highest average responses on the gender skills and professions scales are from students whose mother has earned a postgraduate degree, at 2.44 and 2.45 , respectively. The results of the one-way ANOVA show statistically significant differences on the gender skills and professions scales, with $F$ values at 181.66 and 237.753, respectively ( $p<0.000$ for both).

\section{Discussion}

The results of the study show that the attitudes of male students toward gender roles on the skills and professions scales are more traditional than those of female students, who tend to be nontraditional. This is in line with the results of previous studies (Fan and Marini, 2000; Mensch et al., 2004; Al Kharouf \& Al Bdour, 2006; Japaridze et al., 2013; Hajnalka, 2014). Female students unanimously agreed that the responsibility for setting the dining table, washing clothes, replacing the gas cylinder and ironing lay exclusively with men, and that the professions of journalist, automotive mechanic, taxi driver, and judge must be reserved exclusively for women. This illustrates the females' nontraditional way of thinking and their lack of a balanced gender concept. This also indicates a misconception of female students regarding the concept of gender justice, as they are attempting to combat cultural and social stereotyping based on biological differences between the sexes by showing bias instead for their own sex. As for male youth, their attitudes are traditional and typical, considering that they believe that skills such as training on driving a car, home maintenance, reception of guests, purchase of the newspaper, purchase of household items, and replacement of the gas cylinder must be carried out by men. This reflects the fact that males may refuse to perform any tasks beyond those assigned to them by their society and culture. There was consensus among the participants that the occupation of police officer was not suitable for women. This is strange, as we see female police officers deployed in the streets of Jordan exercising their duties as well as any man. This is likely due to the fact that the intrusion of women into this field is a result of the breaking of stereotypes in Jordanian society. This case, despite its weirdness, reflects the fact that Jordanian society, represented by its young male and female students, still rejects the idea of women taking over men's careers in the police force. Also, the 
students unanimously agreed that the professions of surgeon and anesthesiologist were suitable for males only.

As for the results of the age variable, the students' attitudes toward gender roles on both scales tend to become more balanced as their age increases. This can be attributed to increased maturity as they get older and gain more knowledge and experience. Students in the fourth and fifth year, for example, are more aware of technological progress and cultural openness than first-year students, who spend their first academic year trying to define themselves academically and to understand how things work. This result is different from the results of the studies done by Tinklin et al. (2005), LaFont (2010) and Obare et al. (2013).

The study results showed that the attitudes of students in humanitarian colleges are less traditional than those of students in scientific colleges on the gender scales. This can be explained by the fact that the curriculum and textbooks at humanitarian colleges deal with the concept of gender more often than in scientific colleges. This helps students at humanitarian colleges understand their role in society more clearly, as they can explore this concept more in their studies and research. For students at scientific colleges, their scientific resources and books do not come close to discussing the concept of gender, its perception, or its dimensions. In fact, the two researchers faced a lack of understanding of this concept and its role in socialization when working with students from scientific colleges, while the responses from students at humanitarian colleges were quick and accurate, showing that they had previous knowledge of the subject.

As for the monthly income variable, the study results showed that students' attitudes tend to become more balanced regarding gender as students' families' monthly income and standard of living increases. This result is consistent with the results of El Kharouf and Al Bdour (2006), which showed that women's opportunity to participate in family decisions increased along with the social and economic level of the family. This can be explained by the fact that a better standard of living enables students to mix, travel, study abroad, and interact with other cultures. This makes their definitions less stereotypical with respect to the concepts of masculinity, femininity, and the skills and occupations that both sexes can perform when compared to those with lower living standards. A high standard of living leads to a different lifestyle and, therefore, different concepts and roles are learned from the models surrounding them. This may affect ways of eating, dressing, or education, dealing with persons of the opposite sex, or even prevailing values, which also vary according to differences in living standards.

The place of residence variable also influenced the students' attitudes toward gender roles; they tend to become more gender-balanced as the place of residence moves from outside Amman to East Amman and West Amman. This can be explained by the fact that the socialization and upbringing institutions experienced by the inhabitants of the West Amman regions are relatively different from those encountered by the inhabitants of East Amman or areas outside the capital Amman. Hence, their attitudes are formulated as they define the concepts of masculinity and femininity through different stages of growth according to the surrounding environment. This result is consistent with the results of the studies by Japaridze et al (2013) and Shteiwi (2015).

Finally, the study results showed that as the students' mother's educational level increase, the students' gender attitudes become more balanced and farther from traditional. This is consistent with Fan and Marini (2000). This result confirms the mother's role in the process of socialization, as well as the role of her education, through which she will eventually change the stereotypes regarding both genders and encourage her sons and daughters to exchange roles. The education of the mother allows her to overcome cultural taboos and look at things more scientifically, rather than using a traditional perspective inherited from older generations. Ignorance and illiteracy serve as a closed circle, such that the uneducated mother is trapped and tries to raise sons and daughters as she was raised, and any deviation from the rules with which she was raised is seen as disobedience.

\section{Conclusion}

The achievement of a fair gender society requires that the attitudes of its members be genderbalanced, gender-neutral, and unbiased. Given the biological differences between the sexes, we 
believe in their existence as a basis for interaction between the genders, and not for discrimination between them. Achieving gender equality requires a change in the practice of socialization in all institutions, including education institutions, and especially higher education. Therefore, the results of this study highlight the need to review the patterns of socialization inherited through the educational system in general and in universities in particular, and to use a balanced educational approach that seeks to reproduce unbiased social structures.

Moreover, this study calls for the institutionalization of the concept of gender in higher education institutions by training university professors to apply it during the educational process. University professors can play a major role in changing students' traditional gender roles through the concept of gender identification. Teachers have a power similar to parental authority, whereby students interpret the process of personal identification of their teacher, whether male or female, and acquire his/her gender roles.

The study results reflect the students' lack of understanding of the concept of gender and its social and cultural dimensions. Therefore, it is necessary to reconsider the teaching curricula to work to eliminate traditional gender stereotypes, activating the role of women in curriculum formulation. In addition to developing curricula focused on the concept of gender, the components of this concept, including its social and cultural dimensions, ought to be taught to all university students as a mandatory requirement. It is through freedom from the social and cultural constraints that hinder individuals in our society, from the duality of discourse, and from the stereotyped and traditional conceptual images inherited from our grandparents that we can reach optimal gender balance and equality.

\section{References}

Al Kharouf, A., \& Al Bdour, T. (2006). Gender roles, which the youth develop within the jordanian family, a field study conducted in Tafilah City. Dirasat Journal, 33(6), 539-568.

Bandura, A. (2002). Social learning theory. Englewood Cliffs, NJ: Prentice-Hall.

Baruch, G. K., \& Barnett, R. C. (1986). Fathers Participation in Family Work and Childrens SexRole Attitudes. Child Development,57(5), 1210. doi:10.2307/1130444

Bem, S. L. (1983). Gender Schema Theory and Its Implications for Child Development: Raising GenderAschematic Children in a Gender-Schematic Society. Signs: Journal of Women in Culture and Society, 8(4), 598-616. doi:10.1086/493998

Berger, P. L., \& Luckmann, T. (1991). The social construction of reality: A treatise in the sociology of knowledge. London: Penguin Books.

Bryson, V. (1995). Feminist political theory: An introduction. Basingstoke: Macmillan.

CEDAW. (2016). Consideration of reports submitted by States parties under article 18 of the Convention- Sixth periodic report of States parties due in 2016 - Jordan (6). Retrieved from United Nations website:file:///C:/Users/USER/AppData/Local/Packages/Microsoft.MicrosoftEdge_8wekyb3d8b bwe/TempState/Downloads/N1519331\%20(2).pdf

Chodorow, Nancy (1978) The Reproduction of Mothering: Psychoanalysis and the Sociology of Gender, Berkeley: University of California Press.

Chodorow, N. J. (1992). Feminism and Psychoanalytic Theory. Yale U.P.

Eagly, A. H., Wood, W., \& Diekman, A. B. (2000). Social role theory of sex differences and similarities: A current appraisal. In T. Eckes, \& H. M. Trautner (Eds.), The developmental social psychology of gender (pp. 123174). Mahwah, New Jersey: Erlbaum.

Eisenstein, Z. (1999). Constructing a Theory of Capitalist Patriarchy and Socialist Feminism. Critical Sociology, 25(2-3), 196-217. doi:10.1177/08969205990250020901

Evertsson, M. (2006). The reproduction of gender: Housework and attitudes towards gender equality in the home among Swedish boys and girls. The British Journal of Sociology,57(3), 415-436. doi:10.1111/j.14684446.2006.00118.x

Fan, P., \& Marini, M. M. (2000). Influences on Gender-Role Attitudes during the Transition to Adulthood. Social Science Research,29(2), 258-283. doi:10.1006/ssre.1999.0669

Foshee, V., \& Bauman, K. (1992). Gender Stereotyping and Adolescent Sexual Behavior: A Test of Temporal Order1. Journal of Applied Social Psychology,22(20), 1561-1579. doi:10.1111/j.15591816.1992.tb01757.x

Hajnalka, F. (2014). Gender role attitudes among higher education students in a borderland CentralEastern European region called 'Partium'. CEPS Journal, 4(2), 49-70. 
Harrison, L. A., \& Lynch, A. B. (2005). Social Role Theory and the Perceived Gender Role Orientation of Athletes. Sex Roles, 52(3-4), 227-236. doi:10.1007/s11199-005-1297-1

Hess, M., Ittel, A., \& Sisler, A. (2014). Gender-specific macro- and micro-level processes in the transmission of gender role orientation in adolescence: The role of fathers. European Journal of Developmental Psychology,11(2), 211-226. doi:10.1080/17405629.2013.879055

Inglehart, R., \& Norris, P. (2003). Rising tide: Gender equality and cultural change around the world. Cambridge: Cambridge Univ. Press.

Japaridze, E., Zhghenti, N., Barkaia, M., \& Amashukeli, M. (2013, July). Gender Attitudes and Perceptions among Young People in Georgia [PDF]. Center for Social Sciences.

Kessler, S. J., \& McKenna, W. (2001). Gender: An ethnomethodological approach. Chicago: Univ. of Chicago Press.

LaFont, S. (2010). Beliefs and attitudes toward gender, sexuality, and traditions amongst Namibian youth. Windhoek, Namibia: Gender Research \& Advocacy Project, Legal Assistance Centre.

Lindsey, L. L. (2015). Gender Roles: A Sociological Perspective. Abingdon, Oxon: Taylor and Francis.

Lippmann, W. (1994). Public opinion. New York, NY: Free Press

Martin, C. L., Ruble, D. N., \& Szkrybalo, J. (2002). Cognitive theories of early gender development. Psychological Bulletin, 128(6), 903-933. doi:10.1037//0033-2909.128.6.903

Mensch, B. S., Ibrahirn, B. L., Lee, S. M., \& El-Gibaly, O. (2004). Gender-role Attitudes among Egyptian Adolescents. Studies in Family Planning,34(1), 8-18. doi:https://doi.org/10.1111/j.17284465.2003.00008.x

Oakley, A. (1991). Sex, Gender and Society (1st ed.). London: Routledge.

Obare, F., Agwanda, A., \& Magadi, M. (2013). Gender-Role Attitudes and Reproductive Health Communication among Female Adolescents in South Nyanza, Kenya1. African Population Studies,21(1). doi:10.11564/21$1-349$

Ollenburger, J. C., \& Moore, H. A. (1992). A sociology of women; the intersection of patriarchy, capitalism, and colonization. New Jersey: Prentice Hall.

Reliefweb. (2017, February 16). Committee on the Elimination of Discrimination against Women examines the report of Jordan - Jordan. Retrieved from https://reliefweb.int/report/jordan/committee-eliminationdiscrimination-against-womenexamines-report-jordan.

Sadker, D. M., Sadker, M., Zittleman, K. R. (2009). Still failing at fairness: How gender bias cheats girls and boys in school and what we can do about it. New York: Scribner.

Sharabi, H. (1992). Neopatriarchy: A theory of distorted change in Arab society. New York: Oxford University Press.

Shteiwi, M. (2015). Attitudes towards Gender Roles in Jordan. British Journal of Humanities and Social Sciences, 12(2), 15-27.

Starr, C. R., \& Zurbriggen, E. L. (2016). Sandra Bem's Gender Schema Theory After 34 Years: A Review of its Reach and Impact. Sex Roles, 76(9-10), 566-578. doi:10.1007/s11199-016-0591-4

Tallichet, S. E., \& Willits, F. K. (1986). Gender-Role Attitude Change of Young Women: Influential Factors from a Panel Study. Social Psychology Quarterly, 49(3), 219. doi:10.2307/2786804.

Tinklin, T., Croxford, L., Ducklin, A., \& Frame, B. (2005). Gender and Attitudes to Work and Family Roles: The View of Young People at the Millennium. Gender and Education, 17(2), 129-142.

Updegraff, K. A., Mchale, S. M., Zeiders, K. H., Umaña-Taylor, A. J., Perez-Brena, N. J., Wheeler, L. A., \& Jesús, S. A. (2014). Mexican-American Adolescents' Gender Role Attitude Development: The Role of Adolescents' Gender and Nativity and Parents' Gender Role Attitudes. Journal of Youth and Adolescence,43(12), 2041-2053. doi:10.1007/s10964-014-0128-5

Watts, R., \& Borders, L. (2005). Boys Perceptions of the Male Role: Understanding Gender Role Conflict in Adolescent Males. The Journal of Mens Studies, 13(2), 267-280. doi:10.3149/jms.1302.267

Wharton, A. S. (2012). The sociology of gender: An introduction to theory and research. Malden, MA: WileyBlackwell.

Wijewardene, K. (2016). Are Male University Students' Perception of Female Gender role Differs with Higher Education and Discipline of Study?. Austin J Womens Health, 3(1): 1021. 
Appendix 1

Weights of the gender skills scale

\begin{tabular}{|c|l|l|l|l|}
\hline$\#$ & Skill & Male & Female & Both \\
\hline 1. & Setting the table & Nontraditional & Traditional & Balanced Attitude \\
\hline 2. & Washing the dishes & Nontraditional & Traditional & Balanced Attitude \\
\hline 3. & Washing the clothes & Nontraditional & Traditional & Balanced Attitude \\
\hline 4. & Buying the newspaper & Traditional & Nontraditional & Balanced Attitude \\
\hline 5. & Using the Internet & Traditional & Nontraditional & Balanced Attitude \\
\hline 6. & Buying household items & Traditional & Nontraditional & Balanced Attitude \\
\hline 7. & Replacing gas cylinder & Traditional & Nontraditional & Balanced Attitude \\
\hline 8. & Ironing & Nontraditional & Traditional & Balanced Attitude \\
\hline 9. & Reception of guests & Traditional & Nontraditional & Balanced Attitude \\
\hline 10. & Home maintenance & Traditional & Nontraditional & Balanced Attitude \\
\hline 11. & Training on car driving & Traditional & Nontraditional & Balanced Attitude \\
\hline 12. & Cooking & Nontraditional & Traditional & Balanced Attitude \\
\hline
\end{tabular}

Weights of the gender professions scale

\begin{tabular}{|c|c|c|c|c|}
\hline$\#$ & Profession & Male & Female & Both \\
\hline 1. & Teaching & Nontraditional & Traditional & Balanced Attitude \\
\hline 2. & Working in the press & Traditional & Nontraditiona & 1|Balanced Attitude \\
\hline 3. & Defense careers (such as military and civil defense) & Traditional & Nontraditiona & Balanced Attitude \\
\hline 4. & Holding a ministerial post & Traditional & Nontraditiona & Balanced Attitude \\
\hline 5. & TV or radio director & Traditional & Nontraditiona & Balanced Attitude \\
\hline 6. & Management (companies, factories, individuals, institutions) & Traditional & Nontraditiona & Balanced Attitude \\
\hline 7. & Nursing & Nontraditional & Traditional & Balanced Attitude \\
\hline 8. & Presenting television or radio programs & Nontraditional & Traditional & Balanced Attitude \\
\hline 9. & Agricultural work & Traditional & Nontraditiona & Balanced Attitude \\
\hline 10. & Secretarial work & Nontraditional & |Traditional & Balanced Attitude \\
\hline 11. & Working in police (traffic, criminal investigation) & Traditional & Nontraditiona & 1|Balanced Attitude \\
\hline 12. & Aircraft pilot & Traditional & Nontraditiona & Balanced Attitude \\
\hline 13. & Work in the general intelligence & Traditional & Nontraditiona & Balanced Attitude \\
\hline 14. & Taxi driver & Traditional & Nontraditiona & Balanced Attitude \\
\hline 15. & Judge & Traditional & Nontraditiona & Balanced Attitude \\
\hline 16. & Car mechanic & Traditional & Nontraditiona & Balanced Attitude \\
\hline 17. & Working in construction (selling, buying, building, leasing lands and he & Traditional & Nontraditiona & Balanced Attitude \\
\hline 18. & Ambassador of the state & Traditional & Nontraditiona & Balanced Attitude \\
\hline 19. & Air host/hostess & Nontraditional & Traditional & Balanced Attitude \\
\hline 20. & Lawyer & Traditional & Nontraditiona & Balanced Attitude \\
\hline 21. & Engineering professions & Traditional & Nontraditiona & Balanced Attitude \\
\hline 22. & Sewing work & Nontraditional & Traditional & Balanced Attitude \\
\hline 23. & Gynecology and obstetrics & Nontraditional & Traditional & Balanced Attitude \\
\hline 24. & Surgery and anesthesia & Traditional & Nontraditiona & Balanced Attitude \\
\hline 25. & Producing television or radio programs & Traditional & Nontraditiona & Balanced Attitude \\
\hline
\end{tabular}

